\title{
RECOMMENDED TRITIUM SURFACE CONTAMINATION RELEASE GUIDES
}

\section{March 1991}

\author{
Prepared by: \\ DOE Tritium Surface Contamination Limits Committee \\ John R. Johnson, Chairman \\ . Douglas G. Draper \\ Judith D. Foulke \\ Ronald S. Hafner \\ Roland A. Jalbert \\ William E. Kennedy \\ David S. Myers \\ Charles D. Strain \\ 1
}

U.S. Department of Energy 


\section{DISCLAIMER}

This report was prepared as an account of work sponsored by an agency of the United States Government. Neither the United States Government nor any agency Thereof, nor any of their employees, makes any warranty, express or implied, or assumes any legal liability or responsibility for the accuracy, completeness, or usefulness of any information, apparatus, product, or process disclosed, or represents that its use would not infringe privately owned rights. Reference herein to any specific commercial product, process, or service by trade name, trademark, manufacturer, or otherwise does not necessarily constitute or imply its endorsement, recommendation, or favoring by the United States Government or any agency thereof. The views and opinions of authors expressed herein do not necessarily state or reflect those of the United States Government or any agency thereof. 


\section{DISCLAIMER}

Portions of this document may be illegible in electronic image products. Images are produced from the best available original document. 


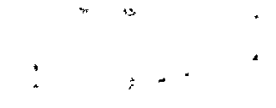




\section{SUMMARY}

This document was prepared to provide scientific basis for recommended changes in specific limits for tritium surface contamination in DOE Order 5480.11. A summary of the physical and biological characteristics of tritium has been provided that illustrate the unique nature of this radionuclide when compared to other pure beta emitters or to beta-gamma emitting radionuclides.

This document is divided into nine sections. The introduction and the purpose and scope are addressed in Section 1.0 and Section 2.0, respectively. Section 3.0 contains recommended interpretation of terms used in this document. Section 4.0 addresses recommended methods for evaluating surface contamination. Biological and physical characteristics of tritium compounds are discussed in Section 5.0, as they relate to tritium radiotoxicity. Scenarios and dose calculations for selected, conservatively limiting cases of tritium intake are given and discussed in Section 6.0 and Section 7.0. Section 8.0 provides conclusions on the information given and recommendations for changes in the surface contamination limits for total tritium to $1 \times 10^{6} \mathrm{dpm}$ per 100 $\mathrm{cm}^{2}$ and removable tritium to $1 \times 10^{5} \mathrm{dpm}$ per $100 \mathrm{~cm}^{2}$. Section 9.0 is a listing of references.

A summary of comments made on the October 1990 draft of this document as received from the members of the DOE Tritium Surface Contamination Limits Committee is contained in the Appendix with a description of the responses provided. 



\section{CONTENTS}

SUMMARY .......................

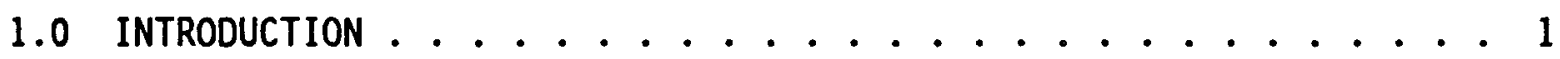

2.0 PURPOSE AND SCOPE ................. 2

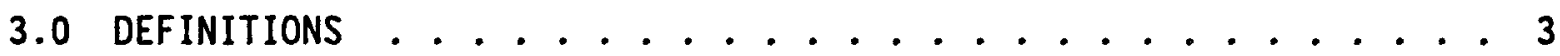

4.0 RECOMMENDED METHODS FOR EVALUATING SURFACE CONTAMINATION . . . . 6

4.1 BREMSSTRAHLUNG MEASUREMENTS . . . . . . . . . . 7

4.2 OUTGASSING MEASUREMENTS . . . . . . . . . . . 7

4.3 SURFACE CONTAMINATION MEASUREMENTS . . . . . . . . 8

5.0 PHYSICAL AND BIOLOGICAL CHARACTERISTICS OF TRITIUM . . . . . 9

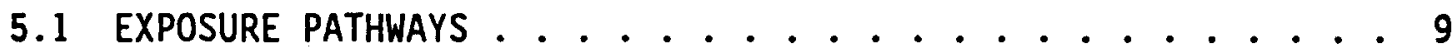

5.2 CHEMICAL AND PHYSICAL FORMS OF TRITIUM ........ 12

6.0 TRITIUM DOSE SCENARIOS . . . . . . . . . . . . 15

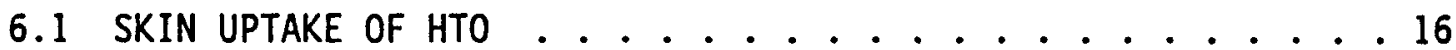

6.2 INHALATION OF HTO ................. 17

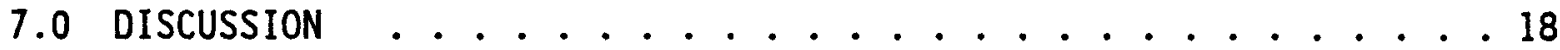

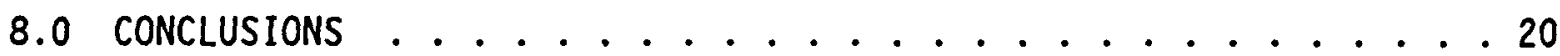

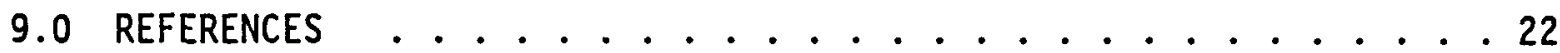




\section{RECOMMENDED TRITIUM SURFACE \\ CONTAMINATION RELEASE GUIDES}

\subsection{INTRODUCTION}

Tritium is a low-energy, pure beta-emitting radionuclide with a half-life of 12.43 years [1]. The low decay energy of tritium (maximum energy $18.60 \mathrm{keV}$; mean energy $5.685 \mathrm{keV}$ [2]) generally requires that tritium must be taken into the body before any radiological damage can occur. Under normal circumstances, tritium does not present an external radiation hazard. When tritium is taken into the body as tritiated water or as tritiated hydrogen gas, it tends to be dispersed throughout the whole body in the normal water of the body tissues. Because of its low beta energy, its dilution throughout all of the soft tissues, and its elimination with an average biological half-life of about 10 days in adults [3], tritium has an extremely low radiological toxicity when compared to other pure beta-emitters, such as phosphorous-32 or strontium-90, or to common beta-gamma emitters, such as iodine-131 or cesium-137.

Despite its physical and biological characteristics, tritium is occasionally grouped with other beta-emitters and/or beta-gamma emitters, as is the case for the surface contamination release limits given in the table of Attachment 2 of DOE Order 5480.11, "Radiation Protection for Occupational Workers" [4]. In that Order, the release of materials and equipment from radiological areas for conditional use in controlled areas is permitted only when the surface contamination limits are less than 
$1,000 \mathrm{dpm}$ per $100 \mathrm{~cm}^{2}$ for removable contamination and less than 5,000 dpm per $100 \mathrm{~cm}^{2}$ for fixed plus removable contamination of beta/gamma emitting radionuclides. These limits cannot be justified for tritium based on the maximum dose that might be received by any individual under these conditions. Hence, recommendations are given for changes to the surface contamination limits for tritium that are different from the limits given for generic beta/gamma emitting radionuclides.

Although specific recommendations in other documents, such as the draft version of the American National Standard Control of Radioactive Surface Contamination on Materials, Equipment, and Facilities to be Released for Uncontrolled Use (ANSI N13.12) [5], are beyond the scope of this report, the limits derived herein should be of interest to regulatory agencies other than the DOE.

\subsection{PURPOSE AND SCOPE}

The purpose of this report is to provide information supporting the establishment of practical limits for permissible tritium surface contamination in the release of materials and equipment from radiological areas to the general public. The limits recommended in this report have been adjusted from those originally promulgated (i.e., tritium grouped with beta-gamma emitters) to reflect acceptable limits specifically for tritium. 
Two topics that are beyond the scope of this report are: 1) contamination limits for materials and equipment that have been exposed to high concentrations of tritium gas for long periods of time and, hence, may have significant tritium concentration below the surface, and 2) the bulk contamination limits for tritiated organic compounds, such as pump oils and "0" rings. Both types of materials can be expected to exhibit tritium induced bremsstrahlung (see Section 3.6) and/or long-term tritium outgassing (see Section 3.7). This subject is discussed in DOE Order 5280.2A, "Radioactive Waste Management" [6].

\subsection{DEFINITIONS}

For purposes of this document, the following definitions apply;

3.1 Protium -- The physical name for the hydrogen isotope of mass 1 . In common tritium usage, the chemical symbol for protium is $\mathrm{H}$.

3.2 Deuterium -- The physical name for the hydrogen isotope of mass 2. In common tritium usage, the chemical symbol for deuterium is $D$.

3.3 Iritium -. The physical name for the hydrogen isotope of mass 3. In common tritium usage, the chemical symbol for tritium is $T$.

3.4 HI -- In this report, unless otherwise noted, the chemical notation for tritium $(T)$ in combination with other hydrogen isotopes $(H, D$, T) to form elemental tritium gas. It will be used here to represent $H T$, DT, and $T_{2}$. 
3.5 HTO -- In this report, the chemical notation for tritiated water in combination with other hydrogen isotopes. It will be used here to represent HTO, DTO, and $\mathrm{T}_{2} \mathrm{O}$.

3.6 Iritium Decay Induced Bremsstrahlung -- Beta particles emitted during tritium decay may indirectly result in an external radiation hazard through the production of a continuous spectrum of low energy $x$-rays, called bremsstrahlung [7]. The amount of tritium induced bremsstrahlung will depend on the material and the total amount of tritium that has been dissolved into or otherwise incorporated into the material. Tritium induced bremsstrahlung has been measured in a variety of materials. Examples include vacuum pump oils, paper products, and various metals [8].

Since the detection of tritium induced bremsstrahlung typically requires tritium amounts ranging upward from tens of millicuries, the subject of tritium induced bremsstrahlung is beyond the scope of this report. This report recommends that materials that produce measurable amounts of tritium induced bremsstrahlung should be disposed of as contaminated waste.

3.7 Outgassing -. The generic term for the evolution of tritium gas into the atmosphere from materials that have been exposed to that gas. Tritium outgassing can be expected from any material that has been exposed to tritium gas, which will continue until the tritium in the material has reached background levels. Real-time monitoring may be used to detect relatively high tritium outgassing levels. This will 
depend on the material and its exposure history, but in general, if tritium outgassing can be detected in real time, the material should be disposed of as contaminated waste.

3.8 Removable Contamination -- The portion of the total tritium surface contamination (see Section 3.10) which is removable or transferable under normal working conditions. The removable tritium surface contamination is assumed to be identical with that which can be measured directly through the use of routine smear survey measurements and liquid scintillation counting techniques. This definition applies to the "Removable" category given in DOE Order $5480.11[4]$.

\subsection{Total Tritium Surface Contamination -- The total tritium activity} absorbed upon, and/or adsorbed into, the surface of the material. This definition applies to the "Fixed plus Removable" category given in DOE Order 5480.11 [4].

The total tritium surface contamination cannot be accurately determined by any method. Direct methods will not detect all tritium activity below the surface (i.e., "Fixed") due to the short range of the tritium beta particles and indirect methods generally provide only a reasonable estimate of the "removable" contamination at the time of measurement.

3.10 Removal Fraction $\left(F_{r}\right)$-- The fraction of the total tritium surface contamination (Section 3.9) that is readily removable (Section 3.8 ) 
or readily transferable to skin surfaces under normal working conditions. A value of 0.1 can be assumed for $F_{r}[9]$, or alternatively, it can be determined experimentally if the items being considered for release are of a routine and consistent nature, so that the experimentally determined value for one item can be applied to another.

\subsection{RECOMMENDED METHODS FOR EVALUATING SURFACE CONTAMINATION}

Tritium contamination of surfaces is a complex process, and it depends on a number of different factors. The major factors are,

- Composition of surface

- Is it metal, glass, plastic, etc.?

- External chemical/physical surface characteristics

- It is polished, machined, etc.?

- Is it clean, covered with oil, paint, corrosion, water vapor, other moisture, etc.?

- Is there vibration, impact, expansion, contraction, ambient pressure/temperature changes, etc.?

- Chemical/physical form of the tritium on the surface

- Is it elemental, water, organic, particulate (such as a metal tritide), etc.?

When discussing tritium contamination of surfaces, it should be noted that the tritium will exist both on the surface and in the surface material [9]. A certain fraction of the tritium on the surface will 
diffuse into the material (except for particulate material) and will likely penetrate to a depth in the material that will prevent direct or indirect measurement. Diffusion of tritium in the material back to the surface will occur over time, leading to additional removable contamination or volatile forms of tritium. These facts, combined with the difficulty in making direct measurements due to the lack of penetrating photon or high energy beta particle emissions from tritium, make the measurement of tritium surface contamination, and its interpretation, difficult.

Although extensive discussions on the full range of tritium measurement techniques can be found in the literature $[9,10,11]$, three are of particular interest to this report: bremsstrahiung measurements, outgassing measurements, and measurement of tritium surface contamination. Each measurement technique is discussed below in decreasing order of the relative radiological hazard.

4.1 Bremsstrahlung Measurements -- Bremsstrahlung measurements should be conducted with a standard GM survey instrument equipped with a standard, thin-window probe. Should the presence of tritium induced bremsstrahlung be detected, high tritium levels on or in the surface material are indicated.

\subsection{Iritium Outgassing Measurements -- Superficial outgassing} measurements should be conducted with a portable ionization chamber monitor capable of detecting airborne tritium concentrations down to approximately $1 \mu \mathrm{C} i$ per $\mathrm{m}^{3}$. More precise 
and sensitive outgassing measurements should be conducted using a closed-loop, recirculating system of known volume which is equipped with an in-line ionization chamber [8]. (Small volume systems that are used for such measurement techniques are quite sensitive and, as with all monitoring equipment, care should be taken to prevent cross-contamination of the monitor, and/or the monitoring system.)

As discussed in Section 3.7, if tritium bremsstrahlung or tritium outgassing is detected, the item should not be considered for release under the recommendations of this report. In general, it is recommended that such items should be disposed of as contaminated waste, unless extensive decontamination is done.

\subsection{Surface Contamination Measurements -- "Removable" surface} contamination measurements should be conducted using standard smear sampling and liquid scintillation counting techniques. The total tritium surface contamination, or "Fixed plus Removable" level should then be determined as discussed in Section 3.10. If the contamination level is below 1/10th the release limit given in Section 8, then the item can be released. For an item whose surface contamination is determined to be greater than $1 / 10$ th the release limit given in Section 8 but less than the release limit, follow-up measurements should be conducted at regular time intervals to verify that the surface contamination of the item to be released is below the release limit. The determined tritium levels in the smear area should be decreasing with time if tritium 
within the material is being depleted by diffusion to the surface. However, constant tritium levels in the smear area for follow-up measurements indicate significant tritium contamination within the material. Such items should be disposed of as contaminated waste.

Should there be any doubt as to the status of the item after an extended series of follow-up tests, the item should be disposed of as contaminated waste, or undergo extensive decontamination.

\subsection{PHYSICAL AND BIOLOGICAL CHARACTERISTICS OF TRITIUM}

Two general factors must be considered when evaluating potential doses received from contact with tritium contaminated surfaces. These are the exposure pathway, and the physical and chemical form of the tritium present. Each of these factors is examined for its potential to contribute to doses from tritium.

5.1 Exposure Pathways -- Tritium contamination in or on surfaces can result in doses to individuals in four different ways: external radiation, inhalation, ingestion, and skin absorption.

5.1.1 External Radiation -- At low levels of tritium surface contamination, where releases of materials and equipment might be considered, significant emission of low energy bremsstrahlung will not occur (see Section 3.6). The 
maximum energy of the tritium beta particle is only $18.6 \mathrm{keV}$. Therefore, as noted in Section 1.0, the maximum range of these particles in tissue is only about $6 \mu \mathrm{m}$. Since the depth of cells in the skin is greater than $30 \mu \mathrm{m}$ [12] and the radio-sensitive tissue of the eye is at a depth of $3 \mathrm{~mm}$ [13], the beta radiation from tritium does not represent an external radiation hazard.

5.1.2 Inhalation -- The inhalation pathway needs to be considered if tritiated gases and/or particulates become airborne. Usually airborne tritium can be expected to be present as HT and/or HTO. Inhalation of HTO and HT compounds has been extensively studied $[14,15,16]$. Exposures to airborne tritiated organic compounds, airborne tritiated particulates and tritides, and other tritiated gases have been seen in the workplace [9]. However less is known about these compounds, and dosimetry models do not generaliy exist for specific compounds.

5.1.3 Ingestion -- This route of uptake of tritium should only be expected from the ingestion of food or liquids that have been contaminated by handling after handling tritium contaminated surfaces. Since it is conservatively assumed (see Section 5.1.4) that all tritium that gets onto the hands will be absorbed into and/or through the skin, the ingestion route of exposure can be disregarded for the purpose of this report as it will not be the most limiting. 
5.1.4 Skin Absorption -- By the 1ate 1950s, Pinson and Langham [14], and DeLong, Thompson and Kornberg [17], had independently shown that HTO can be readily absorbed through the skin in both the liquid and vapor phase. Osborne [18] showed that the intake of HTO vapor in air by this route was approximately equal to one half the intake via inhalation, assuming a breathing rate of $20 \mathrm{~L}$ per min during light work. The ICRP [3] recommends that the inhalation rate be increased by a factor of 1.5 to account for skin absorption from tritiated water vapor.

No significant skin absorption of HT in air occurs. However, studies by Vaughan and Davis [19], found that high concentrations of tritium gas absorbed on various metals and glass can be transferred to the skin by contact. Further studies by Hutchin and Vaughan [20], Eakins et al. [21,22], and by Johnson et a1. $[23,24]$, have shown that if skin comes into contact with surfaces that have been exposed to high concentrations of HT gas, significant uptake and retention of tritium occurs in the skin, as well as in other organs. The processes by which this occurs are not fully understood.

As described above, inhalation and skin absorption will be the limiting routes of tritium intake that need to be considered for tritium surface contamination limits. While ingestion may also occur, it will not be limiting for surface contamination limits because of the assumptions used. External radiation from tritium 
does not present a radiation hazard, and thus need not be considered.

5.2 Chemical and Physical Forms of Tritium -- Since the uptake and retention, and hence the dose, of tritium will depend on the chemical and physical form of the tritium that is on the surface, these factors are important in evaluating potential doses. While HTO and HT are usually the principal tritium forms present, different forms could also be present and are discussed below.

\subsubsection{Tritiated water (HTO) -- The dosimetry for this form of} tritium is well known. Intakes can occur from skin contact with contaminated surfaces or from the inhalation of air contaminated by HTO evaporating or outgassing from surfaces. The committed effective dose equivalent is $1.7 \times 10^{-11} \mathrm{~Sv}^{\mathrm{a}}$ per $\mathrm{BQ}$ intake [3], or $6.3 \times 10^{-5}$ rem per $\mu \mathrm{Ci}$ intake.

5.2.2 Surfaces contaminated by HT -- The chemical/physical form of tritium on or in surfaces from $H T$ gas is unknown, but Surrette and MCETroy [25] found that it was tenaciously retained on/in staintess stee]. Recent measurement $[24,26]$ in rats allows a direct assignment of skin dose from tritium surface contamination. Data from these references have been combined to provide an estimate of skin dose at the point of contact: $3 \times 10^{-9} \mathrm{~Sv}$ per $\mathrm{Bq} / \mathrm{cm}^{2}$. This dose is assumed to

a 1 sievert $(S V)=100$ rem and 1 becquerel $(B q)=2.7 \times 10^{-5} \mu \mathrm{Ci}$. 
result only from the intake of tritium, with no contribution from external radiation. Experiments are currently being conducted to clarify the extent and magnitude of doses to other tissues that may result from tritium transmitted through the skin in this manner. However, based on current understanding $[23,24,26]$, it is thought that the skin dose will be more than 10 times the committed effective dose equivalent, making the skin dose the limiting factor.

Even though material exposed to high concentrations of HT may be flagged for disposal as contaminated waste by results of bremsstrahiung or outgassing measurements (see Sections 4.1 and 4.2 ), contact with this form of tritium surface contamination may occur during other handling.

\subsubsection{Metal tritides -- Some metal tritides are known to} spontaneously oxidize in air at respirable ${ }^{b}$ sizes $(<100 \mu \mathrm{m}$ AMAD) depending on the metal, with either HT or HTO being produced. Others may not spontaneously oxidize. No information is known to exist by which the dose from inhalation of small particles of these metal tritides can be evaluated. As a first approximation, they could be treated as a Class $Y$ compound [3]. However, if the organically bound tritium seen by Eakins et a]. [21,22] and others $[24,26]$ is also produced in the lungs from tritide particles nose, and thus, can be termed "respirable" 
in contact with tissue in the lung, the estimation of doses from tritide particles will need reevaluation.

Despite these difficulties, metal tritide particles should not cause a concern outside of radiological areas since they should be easily cleaned from surfaces before the material is released from radiological areas.

\subsubsection{Low molecular weight organic compounds -- There is no} generally accepted dosimetry model for these compounds. Most will be catabolized quickly in the human body, resulting in HTO production, or will be excreted directly. It is conservatively assumed that the intakes, and the dose per microcurie intake is the same for these compounds as for HTO. These compounds should not pose a concern outside radiological areas since they are readily removed from surfaces by standard decontamination procedures.

\subsubsection{High molecular weight organic compounds, such as DNA} precursors -- Again there is no generally accepted dosimetry model for these compounds. Following the recommendation of the ICRP [3], the dose per microcurie intake can be taken to be 10 times that of HTO. In general, these compounds are not volatile and should not result in airborne tritium from surface contaminations. Since the skin forms a good barrier for these compounds, skin uptake should not be a factor. Therefore, it is unlikely that these compounds would be more 
limiting than HTO. Again, these compounds should not pose a concern outside radiological areas since they are readily removed from surfaces by standard decontamination procedures.

As discussed in the preceding sections, HTO- and HT-contaminated surfaces will result in the largest doses per unit of tritium surface contamination and hence only these two compounds need to be considered. Low molecular weight organic compounds can be treated as HTO, as this will be conservative. Surfaces contaminated by high molecular weight organic compounds can also be treated as HTO since the combination of low uptake through skin and low volatility will make this a conservative assumption. Decontamination of surfaces contaminated with both types of organic compounds should lead to very low levels of residual tritium contamination. Surfaces contaminated by metal tritides should also be easily decontaminated to very low levels.

\subsection{TRITIUM DOSE CALCULATIONS}

of the exposure pathways and the chemical and physical forms considered above, the limiting combinations are:

- Inhalation or skin uptake of HTO -- In this case, the dose that needs to be calculated is the committed effective (whole body) dose 
equivalent. Standard models recommended by ICRP [3] can be used which result in a committed effective dose equivalent of $1.7 \times 10^{-11} \mathrm{~Sv}$ per $\mathrm{Ba}$ intake. Intakes for various limiting scenarios are discussed below.

- Skin contamination from HT contaminated surfaces -- In this case, the skin dose can be estimated directly from experiments conducted on rats $[24,26]$. As stated above, the skin dose for rats in these experiments was $3 \times 10^{-9} \mathrm{~Sv}$ per $\mathrm{Bq} / \mathrm{cm}^{2}$. Since no other dose estimates are available for these situations, this dose factor will be assumed.

Exposure to HTO contaminated surfaces is, therefore, the only scenario that need to be further evaluated.

6.1 Skin Uptake of HTO -- For the purpose of this calculation, it is assumed that a $200 \mathrm{~cm}^{2}$ surface is contaminated with tritium at a level of $1 \mathrm{~Bq}$ per $\mathrm{cm}^{2}$. (This size was chosen since the contact area between hands and a tritium contaminated object that might be picked up is generally assumed to be $200 \mathrm{~cm}^{2}$ ). When all of the removable tritium (see Section 3.7) on the surface is assumed to be taken into the body, the intake will be $20 \mathrm{~Bq}$ for contact with the surface $\left(200 \mathrm{~cm}^{2}\right.$ multiplied by $F_{r}=0.1$ to convert from total tritium contamination to removable tritium contamination). The dose that will result from such contact is found by multiplying the uptake by the committed effective dose equivalent per Bq intake, i.e., $20 \times\left(1.7 \times 10^{-11}\right)=3.4 \times 10^{-10}$ sv per $\mathrm{Bq} / \mathrm{cm}^{2}$. 
6.2 Inhalation of HTO -- For the purposes of this calculation, it is assumed that the total surface area of the object being removed from the tritium radiological area is $1 \mathrm{~m}^{2}$. This would correspond to a square box about 1 foot on a side, with all 12 surfaces being equally contaminated. This contamination is assumed to leave the surface and become airborne (exchange with water vapor in air) with a half-time of $1 \mathrm{hr}$. Furthermore, it is assumed that this HTO vapor is uniformly distributed in a small $\left(20 \mathrm{~m}^{3}\right)$ occupied room, with a very low (one air change per hour) ventilation rate. It is conservatively assumed that this room is continuously occupied by a person breathing air at $1.2 \mathrm{~m}^{3}$ per hr. (Note that skin uptake of HTO vapor results in an "effective" breathing rate of $1.8 \mathrm{~m}^{3}$ per $\mathrm{hr}$.

With these assumptions, the fraction of the tritium that is taken in by an individual residing continuously in the room is approximately $\left(1.8 \mathrm{~m}^{3} / \mathrm{hr}\right) /\left(20 \mathrm{~m}^{3} / \mathrm{hr}\right)=0.09$. That is, $9.0 \%$ of the tritium on the surface is assumed to be inhaled. For a surface contamination of $1 \mathrm{~Bq}$ per $\mathrm{cm}^{2}$ for the object, an intake of $9.0 \mathrm{x}$ $10^{2} \mathrm{~Bq}$ would occur, resulting in a committed effective dose equivalent of $1.5 \times 10^{-8} \mathrm{~Sv}$ per $\mathrm{Ba} / \mathrm{cm}^{2}$.

It is instructive to note that this fraction is independent of the rate that tritium evolves from the surface, and only depends on the relative magnitude of the breathing rate (plus skin uptake) and the room ventilation rate. It should also be noted that the combination of a $20 \mathrm{~m}^{3}$ volume room, a $1 \mathrm{~m}^{2}$ surface, one air change 
per hour, and continuous occupancy is likely conservative. As an example, equipment with larger surfaces could be assumed in the calculations, but it is unlikely that they would be put into such a small room with essentially no ventilation, with somebody residing in it continuously.

\subsection{DISCUSSION}

Various routes of tritium uptake that are possible from tritium contaminated surfaces have been reviewed here. As developed in this report, the largest doses from exposure to tritium contaminated surfaces would occur if the tritium was in the form of either HTO or HT. The limiting route of exposure for HTO would be either skin uptake or inhalation (in which case the effective (whole body) dose equivalent would be of concern); while for HT, skin uptake would be limiting (where the skin dose would be of concern).

Using values available from the literature on animal studies, and the crude, but conservative, exposure scenarios described in Section 6.0, the committed effective dose equivalents calculated for any one "contact" by an individual are given in Table 1: 
Table 1.

Committed Effective Dose Equivalent Resulting After

One Contact with Surfaces Contaminated with Tritium*

\begin{tabular}{|c|c|c|c|}
\hline & & se $(S v)$ per & \\
\hline & Inhalation & Skin Uptake & Skin Retention \\
\hline HTO & $1.5 \times 10^{-8}$ & $3.4 \times 10^{-10}$ & - \\
\hline HT (skin dose) & - & - & $3 \times 10^{-9}$ \\
\hline & & & \\
\hline & & se (mrem) per & $1 / \mathrm{cm}^{2}$ \\
\hline & Inhalation & Skin Uptake & Skin Retention \\
\hline HTO & 55.5 & 1.3 & - \\
\hline HT & - & - & 11.1 \\
\hline & & & \\
\hline & & mrem) per dpr & $\mathrm{cm}^{2}$ \\
\hline & Inhalation & Skin Uptake & Skin Retention \\
\hline HTO & $2.5 \times 10^{-7}$ & $5.7 \times 10^{-9}$ & - \\
\hline HT & - & - & $5 \times 10^{-8}$ \\
\hline
\end{tabular}

Values are given in both SI and traditional units.

$\dagger$ This is committed dose equivalent for skin, which can be multiplied by a weighting factor of 0.01 for comparison to the committed effective dose equivalent given for inhalation and skin uptake.

It can be seen that the HTO inhalation route gives the largest committed effective dose equivalent per unit tritium surface contamination. In traditional units, the largest committed effective dose equivalent would be $2.5 \times 10^{-7} \mathrm{mrem}$ per $\mathrm{dpm} / 100 \mathrm{~cm}^{2}$. Therefore, the largest committed 
effective dose equivalent that could result from release of an item having a total tritium surface contamination (i.e., fixed plus removable) at the current levels stated in DOE Order 5480.11, Appendix 2 , is calculated to be $1.3 \times 10^{-3} \mathrm{mrem}$. That is, (5000 dpm per $100 \mathrm{~cm}^{2}$ ) $\times\left(2.5 \times 10^{-7} \mathrm{mrem}\right.$ per $\left.\mathrm{dpm} / 100 \mathrm{~cm}^{2}\right)=1.3 \times 10^{-3} \mathrm{mrem}$.

\subsection{CONCLUSIONS}

The current surface contamination limits, as given in DOE Order 5480.11 [4], were developed so that the maximum committed effective dose equivalent of 1 mrem would not be exceeded if items at the $5 \times 10^{3} \mathrm{dpm}$ per $100 \mathrm{~cm}^{2}$ limit were released. However, when this limit is applied specifically to tritium using the very conservative assumptions developed in this report, the maximum committed effective dose equivalent to an individual would be $1.3 \times 10^{-3} \mathrm{mrem}$. Therefore, the current surface contamination limit in DOE Order 5480.11 is considered to be overly conservative for tritium by a factor of over 700 . A relaxation of the current total tritium surface contamination limit by a factor of 200 (to $1 \times 10^{6} \mathrm{dpm}$ per $100 \mathrm{~cm}^{2}$ ) would result in a maximum committed effective dose equivalent of $0.26 \mathrm{mrem}$, which is still considerably less that the 1 mrem maximum.

Therefore, it is a consensus of this committee that:

- A surface contamination limit specifically for tritium be adopted that is separate from other radionuclides. 
- The new tritium surface contamination limit represent a value that is relaxed by a conservative factor of 200 from that currently given for the beta-gamma emitters.

That is, a total tritium surface contamination limit of $1 \times 10^{6} \mathrm{dpm}$ per $100 \mathrm{~cm}^{2}$ and a removable tritium surface contamination 1 imit of $1 \times 10^{5}$ dpm per $100 \mathrm{~cm}^{2}$ is recommended. These changes applied to the table of surface radioactivity guides in Attachment 2 of DOE Order 5480.11 [9] are given in Table 2. These levels of surface contamination will not result in situations where an individual's committed effective dose equivalent would exceed about $1 \mathrm{mrem}$. ALARA considerations may result in individual organizations establishing administrative control levels below this level.

The draft NUREG, "Residual Radioactive Contamination From Decommissioning - Technical Basis for Translating Contamination Levels to Annual Dose" [27], contains a calculated tritium surface contamination level of $1.8 \times 10^{6} \mathrm{dpm}$ per $100 \mathrm{~cm}^{2}$. This level corresponds to a calculated annual dose of 1 mrem using the procedures and assumptions outlined in the final version of that report ${ }^{c}$. The limit of $1 \times 10^{6} \mathrm{dpm}$ per $100 \mathrm{~cm}^{2}$ recommended in this report is about a factor of 2 lower than the draft NUREG value.

c Personal communication from W. E. Kennedy. 
It should also be noted that the recommendations contained in this report are in full agreement with all present NCRP and ICRP recommendations $[3,28-30]$. 
Table 2. Surface Radioactivity Guides for Attachment 2 for DOE Order 5480.11

\begin{tabular}{|c|c|c|}
\hline NUCLIDE ${ }^{1 /}$ & REMOVABLE $2 / 4 /$ & $\begin{array}{c}\text { TOTAL }^{2 / 3 /} \\
\text { (FIXED PLUS REMOVABLE) }\end{array}$ \\
\hline $\begin{array}{l}U \text {-nat, } U-235, U-238, \\
\text { and as sociated } \\
\text { decay products }\end{array}$ & $1,000 \mathrm{dpm} \alpha / 100 \mathrm{~cm}^{2}$ & $5,000 \mathrm{dpm} \quad \alpha / 100 \mathrm{~cm}^{2}$ \\
\hline $\begin{array}{l}\text { Transuranics, } \\
\text { Ra-226, Ra-228, } \\
\text { Th-230, Th-228, } \\
\text { Pa-231, Ac-227, } \\
\text { I-125, I-129 }\end{array}$ & $20 \mathrm{dpm} / 100 \mathrm{~cm}^{2}$ & $300 \mathrm{dpm} / 100 \mathrm{~cm}^{2}$ \\
\hline $\begin{array}{l}\text { Th-nat, Th-232, } \\
\text { Sr-90, Ra-223, } \\
\text { Ra-224, U-232, } \\
\text { I-126, I-131, } \\
\text { I- } 133\end{array}$ & $200 \mathrm{dpm} / 100 \mathrm{~cm}^{2}$ & $1,000 \mathrm{dpm} / 100 \mathrm{~cm}^{2}$ \\
\hline $\begin{array}{l}\text { Beta-gamma emitters } \\
\text { (nucl ides with } \\
\text { decay modes other } \\
\text { than alpha emission } \\
\text { or spontaneous } \\
\text { fission) except } \\
\text { sr-90 and } \\
\text { others noted above. } 5 /\end{array}$ & $1,000 \mathrm{dpm} \beta-\gamma / 100 \mathrm{~cm}^{2}$ & $5,000 \mathrm{dpm} \beta-\gamma / 100 \mathrm{~cm}^{2}$ \\
\hline Tritium $(H-3)^{6 /}$ & $100,000 \mathrm{dpm} / 100 \mathrm{~cm}^{2}$ & $000,000 \mathrm{dpm} / 100 \mathrm{~cm}^{2}$ \\
\hline
\end{tabular}

1/ Where surface contamination by both alpha- and beta-gamma-emitting nuclides exists, the limits established for alpha- and beta-gammaemitting nuclides should apply independently.

2) As used in this table, dpm (disintegrations per minute) means the rate of emission by radioactive material as determined by correcting the counts per minute observed by an appropriate detector for background, efficiency, and geometric factors associated with the instrumentation. 
3/ The levels may be averaged over one square meter provided the maximum surface activity in any area of $100 \mathrm{~cm}^{2}$ is less than three times the guide values. For purposes of averaging, any square meter of surface shall be considered to be above the activity guide $\underline{G}$ if: (1) from measurements of a representative number of sections it is determined that $1 / n \Sigma_{n} S_{i} \geq G$, where $S_{i}$ is the dis/min-100 $\mathrm{cm}^{2}$ determined from measurements of section $i$; or (2) it is determined that the sum of the activity of all isolated spots or particles in any $100 \mathrm{~cm}_{2}$ area exceeds $3 G$.

4) The amount of removable radioactive material per $100 \mathrm{~cm}^{2}$ of surface area should be determined by wiping that area with dry filter or soft absorbent paper, applying moderate pressure, and assessing the amount of radioactive material on the wipe with an appropriate instrument of know efficiency. (Note - the use of dry material may not be appropriate for tritium.) When removable contamination on objects of surface area less than $100 \mathrm{~cm}^{2}$ is determined, the activity per unit area should be based on the actual area and the entire surface should be wiped. Except for transuranics and Ra-226, Ra-228, Ac-227, Th-228, Th-230, and Pa-231 alpha emitters, it is not necessary to use wiping techniques to measure removable contamination levels if direct scan surveys indicate that the total residual surface contamination levels are within the limits for removable contamination.

5/ This category of radionuclides includes mixed fission products, including the $5 r-90$ which is present in them. It does not apply to Sr90 which has been separated from the other fission products or mixtures where the $\mathrm{Sr}-90$ has been enriched.

6/ These limits do not apply to contamination outside buildings. A value of 0.1 may be assumed for the removal fraction if experimentally determined values are unavailable (see Section 3.10). 


\subsection{REFERENCES}

[1] Unterweger, M.P., B.M. Coursey, R.J. Shima, W.B. Mann. 1980. "Preparation and Calibration of the 1978 National Bureau of Standards Tritiated Water Standards." International Journal of Applied Radiation and Isotopes. $31: 611-614$.

[2] International Commission on Radiological Protection (ICRP). 1983. Radionuclide Transformations: Energy and Intensity of Emissions. Publication 38, Pergamon Press, New York.

[3] International Commission on Radiological Protection (ICRP). 1979. Limits for Intakes of Radionuclides by Workers. Publication 30 , Pergamon Press, New York.

[4] U.S. Department of Energy (DOE). 1988. Radiation Protection for Occupational Workers. DOE Order 5480.11, 12-21-88, Washington, D.C.

[5] American National Standards Institute, Inc. (ANSI). 1978. Draft American National Standard Control of Radioactive Surface Contamination on Materials, Equipment, and Facilities to be Released for Uncontrolled Use. Publication N13.12, ANSI, New York. (In particular, see Appendix B).

[6] U.S. Department of Energy (DOE). 1988. Radioactive Waste Management. DOE Order 5420.2A, Washington, D.C.

[7] Evans, R.D. 1955. The Atomic Nucleus. McGraw-Hill, New York. 
[7] Evans, R.D. 1955. The Atomic Nucleus. McGraw-Hill, New York.

[8] Guide to Good Practices at DOE Tritium Facilities. 1989. MLM-3610. EG\&G Mound Applied Technologies, Miamisburg, Ohio.

[9] International Organization for Standardization (ISO). 1988. Evaluation of Surface Contamination. Part 2: Tritium Surface Contamination. ISO 7503-2:1988(E). ISO, Switzerland.

[10] National Council on Radiation Protection (NCRP). 1976. Tritium Measurement Techniques, Publication 47, NCRP, Bethesda, MD.

[11] National Council on Radiation Protection (NCRP). 1979. Tritium in the Environment, Publication 62, NCRP, Bethesda, MD.

[12] National Council on Radiation Protection (NCRP). 1989. Limit for Exposure to "Hot Particles" on the Skin. Publication 106, NCRP, Bethesda, MD.

[13] International Commission on Radiological Protection (ICRP). 1974. Report of The Task Group on Reference Man. Publication 23, Pergamon Press, New York.

[14] Pinson, E.A., and W.H. Langham. 1957. "Physiology and Toxicology of Tritium in Man." Journal of Applied Physiology 10:108-126. 
[15] Peterman, B.F, J.R. Johnson, R.G.C. MCElroy. 1985. "HT/HTO Conversion in Mammals." Fusion Technology 8:2557-2563.

[16] Ichimasa, M., Y. Ichimasa, N. Hashimoto, M. Oda, Y. Akita. 1988. "Comparison of Oxidation Activity of Tritium Gas Amoung Various Animals and Man - Analysis of Intestinal Bacterial Flora for Oxidation." In Third Japan-US Workshop on Tritium Radiobiology and Health Physics. Institute of Plasma Physics, Nagoya University, Japan.

[17] DeLong, C.W., R.C. Thompson, H.A. Kornberg. 1954. American Journal of Roentgenology 71:1038.

[18] Osborne, R.V. 1966. "Absorption of Tritiated Water Vapour by People". Health Physics 12:1527-1537.

[19] Vaughan, B.E., and A.K. Davis. 1961. "Some Critical Observations Concerning the Handling of High Levels of Tritium Radioactivity." USNRDL TR-505.

[20] Hutchin, M.E., and B.E. Vaughan. 1965. "Skin Contact Transfer of Tritium from Brass." Health Physics 11:1047-1053.

[21] Eakins, J.D., and W.P. Hutchinson. 1969. "The Radiological Hazard from Tritium Absorbed on Meta1 Surfaces, Part 2: The Estimation of the Level of Tritium Contamination on Metal Surfaces by Smearing." AERE-R-5988. 
[22] Eakins, J.D., W.F. Hutchinson, A.E. Lally. 1975. "The Radiological Hazard from Tritium Sorbed on Metal Surfaces." Health Physics $18: 213-224$.

[23] Johnson, J.R., and D.W. Dunford. 1985. "Dosimetric Models of ${ }^{3} \mathrm{H}$ from Skin Absorption Following Contact with $T_{2}$-Contaminated Surfaces." Health Physics 48:110-120.

[24] Johnson, J.R., E.S. Lamothe, J.S. Jackson, R.G.C. McElroy. 1988. "Metabolism and Dosimetry of Tritium from Tritium Gas Contaminated Surfaces." Fusion Technology 14:1147-1152.

[25] Surette, R.A., and R.G.C. McElroy. 1988. "Regrowth, Retention, and Evolution of Tritium from Stainless Steel." Fusion Technology $14: 1141-1146$.

[26] McElroy, R.G.C., E.S. Lamothe, J.S. Jackson. 1989. "The Dosimetry of Tritium from Metal Surfaces." In: Workshop/Symposium on Radiation Protection: Past and Future, Chalk River Nuclear Laboratories, Chalk River, Ontario, Canada.

[27] Kennedy, W.E., Jr., R.A. Peloquin. 1990. Residual Radioactive Contamination From Decommissioning. Technical Basis for Translating Contamination Levels to Annual Dose. Draft Report for Comment. NUREG/CR-5512, PNL-7212, NRC, Washington, D.C. 
[28] International Commission on Radiological Protection (ICRP). 1987. Individual Monitoring for Intakes of Radionuclides by Workers: Design and Interpretation. Publication 54, Pergamon Press, New York.

[29] National Council on Radiation Protection (NCRP). 1985. General Concepts for the Dosimetry of Internally Deposited Radionuclides. Publication 84, NCRP, Bethesda, MD.

[30] National Council on Radiation Protection (NCRP). 1987. Recommendations on Limits for Exposure to Ionizing Radiation. Publication 91, NCRP, Bethesda, MD. 